\title{
Effects of DC Stray Current on the Polarization Characteristics of X70 Steel
}

\author{
Jun Wang, Zili Li ${ }^{*}$, Chuanping Kong, Ziqing Yang, Jianguo Liu, Gan Cui \\ Provincial Key Laboratory of Oil and Gas Storage and Transportation Security, College of Pipeline \\ and Civil Engineering, China University of Petroleum, Qingdao, Shandong, 266580, China \\ *E-mail: zilimenhuzu@ 163.com
}

doi: $10.20964 / 2018.12 .50$

Received: 21 June 2018 / Accepted: 6 August 2018 / Published: 5 November 2018

To investigate polarization characteristics of X70 steel at direct current densities in the $50 \sim 1200 \mathrm{~A} / \mathrm{m}^{2}$ range under anodic and cathodic interferences, electrochemical method was used to test Tafel polarization curves. The critical current density was $180 \mathrm{~A} / \mathrm{m}^{2}$ and equal or above this value the Tafel polarization curves were linear. By fitting these curves, we obtained polarization resistance $R_{\mathrm{p}}$, which can be used to characterize the polarization characteristics of X70 steel at DC current. $R_{\mathrm{p}}$ decreased with an increase in the DC current density under both cathodic and anodic interferences. Relational between $R_{\mathrm{p}}$ and DC current density was calculated. As the anodic interference current density increased, corrosion potential of X70 steel shifted positively. Opposite behavior is observed in the case of cathodic interference.

Keywords: DC stray current; X70 steel; corrosion; linear fitting method; polarization resistance

\section{$\underline{\text { FULL TEXT }}$}

(C) 2018 The Authors. Published by ESG (www.electrochemsci.org). This article is an open access article distributed under the terms and conditions of the Creative Commons Attribution license (http://creativecommons.org/licenses/by/4.0/). 